\title{
Breast health global initiative (BHGI) outline for program development in Latin America
}

\author{
Benjamin O.Anderson, MD, (1) Eduardo Cazap, MD, PhD.(2)
}

\begin{abstract}
Anderson BO, Cazap E. Breast health global initiative (BHGI) outline for program development in Latin America. Salud Publica Mex 2009;5I suppl 2:S309-S3I5.
\end{abstract}

\begin{abstract}
The Breast Health Global Initiative (BHGI) applied an evidence-based consensus review process to develop guidelines for breast cancer early detection, diagnosis, and treatment in low- and middle-income countries (LMCs) including those in Latin America. Breast cancer outcomes correlate with the degree to which I) cancers are detected early, 2) cancers can be diagnosed correctly, and 3) proper multimodality treatment can be provided in a timely fashion. Cancer prevention through health behavior modification may influence breast cancer incidence in LMCs. Diagnosing breast cancer at earlier stages will reduce breast cancer mortality. Programs to promote breast self-awareness and clinical breast examination and resource-adapted mammographic screening are important early detection steps. Screening mammography has been shown to reduce breast cancer mortality, but is cost prohibitive in some settings. Breast imaging, initially with ultrasound and, at higher resource levels with diagnostic mammography, improves preoperative diagnostic assessment and permits image-guided needle sampling. Multimodality therapy includes surgery, radiation, and systemic therapies.
\end{abstract}

Key words: Breast neoplasms, developing countries, physical examination, diagnosis, neoplasm staging, combined modality therapy, guideline, health plan implementation

\author{
Anderson BO, Cazap E. \\ Breast health global initiative (BHGI) planeamiento \\ para el desarrollo de programas en América latina. \\ Salud Publica Mex 2009;5I supl 2:S309-S3I5.
}

\section{Resumen}

La Iniciativa Global para la Salud de la Mama (BGHI) ha aplicado un proceso de revisión de consenso, basado en la evidencia, a fin de desarrollar guías para la detección precoz del cáncer de mama, diagnóstico y tratamiento, en países de bajos y medianos ingresos (PBMI) incluyendo aquellos en América latina. La evolución del cáncer de mama se correlaciona con el grado al cual I) los cánceres son detectados tempranamente 2) los cánceres pueden ser diagnosticados correctamente, y 3) el adecuado tratamiento multimodal suministrado a tiempo. La prevención del cáncer a través de modificaciones de las conductas de salud puede modificar la incidencia del cáncer de mama en PBMI. El diagnóstico del cáncer de mama en estadios iniciales reduce la mortalidad por cáncer de mama. Los programas que promueven el auto-conocimiento de la mama y el examen clínico mamario junto al tamizaje mamográfico adaptado a los recursos son pasos importantes en la detección precoz. El tamizaje mamográfico ha demostrado que reduce la mortalidad por cáncer de mama pero su costo es prohibitivo en algunas situaciones. El diagnóstico por imágenes mamario, inicialmente con ecografía y, en situaciones de mayores recursos con mamografía, mejora la evaluación diagnóstica preoperatoria y permite tomar muestras con aguja guiadas por imágenes. El tratamiento multimodal incluye la cirugía, radiaciones y tratamientos sistémicos.

Palabras clave: neoplasias de la mama, países en desarrollo, examen físico, diagnóstico, estadificación de neoplasias, tratamientos combinados, guías, implementación de planes de salud

(I) Breast Health Global Initiative, Fred Hutchinson Cancer Research Center, University of Washington, Seattle, Washington, USA

(2) International Union Against Cancer (UICC), Sociedad Latinoamericana y del Caribe de Oncología Médica, Buenos Aires, Argentina

Received on: November 3, 2008 - Accepted on: December 15, 2008

Address reprint requests to: Benjamin O.Anderson, MD, Department of Surgery, Box 356410 ,

University of Washington, Seattle, Washington 98195, USA.

E-mail: banderso@u.washington.edu. 
A mong women, breast cancer is the most common cause of cancer-related death worldwide, with case fatality rates highest in low- and middle-income countries (LMCs). Globally, breast cancer is the most common cancer among women, comprising $23 \%$ of all female cancers that are newly diagnosed in more than 1.1 million women each year. ${ }^{1}$ More than 411000 deaths each year result from breast cancer annually, accounting for more than $1.6 \%$ of female deaths from all causes. ${ }^{2}$ Projecting to 2010, the annual global burden of new breast cancer cases will be 1.5 million and an ever-increasing majority will be from LMCs. ${ }^{3}$ Approximately 4.4 million women diagnosed with breast cancer in the last 5 years are currently alive, making breast cancer the single most prevalent cancer in the world. ${ }^{1}$ Despite the common misconception that breast cancer is predominantly a problem of wealthy countries, the majority of breast cancer deaths each year in fact occur in developing rather than developed countries. ${ }^{3}$

\section{Guideline development}

Evidence-based guidelines outlining optimal approaches to breast cancer detection, diagnosis, and treatment have been well developed and disseminated in several highresource countries. ${ }^{4,5}$ These guidelines define optimal practice, and therefore have limited utility in LMCs. Optimal practice guidelines may be inappropriate to apply in LMCs for numerous reasons, including inadequate personal resources, limited health care infrastructure, lack of pharmaceuticals, and cultural barriers. Hence, there is a need to develop clinical practice guidelines oriented toward LMCs, specifically considering and adapting to existing health care resources.

Cosponsored by the Fred Hutchinson Cancer Research Center and Susan G. Komen for the Cure, the Breast Health Global Initiative (BHGI) strives to develop evidence-based, economically feasible, and culturally appropriate guidelines that can be used in nations with limited health care resources to improve breast cancer outcomes. The BHGI held three Global Summits to address health care disparities (Seattle, Washington, 2002), ${ }^{6}$ evidence-based resource allocation (Bethesda, Maryland, 2005), ${ }^{7}$ and guideline implementation (Budapest, Hungary, 2007) ${ }^{8}$ as related to breast cancer in LMCs. Modeled after the approach of the National Comprehensive Cancer Network (NCCN), BHGI developed and applied a consensus panel process now formally endorsed by the Institute of Medicine (IOM) ${ }^{9}$ to create resource-sensitive guidelines for breast cancer early detection, ${ }^{10}$ diagnosis, ${ }^{11}$ treatment, ${ }^{12}$ and health care systems, ${ }^{13}$ as related to breast health care in LMCs. The BHGI guidelines are intended to assist ministers of health, policymakers, administrators, and institutions in prioritizing resource allocation as breast cancer treatment programs are implemented and developed in their resource-constrained countries. Key findings of the BHGI guidelines are summarized below.

\section{Breast cancer prevention}

Health behaviors that may reduce risk for breast cancer include prolonged lactation, regular physical activity, weight control, avoiding excess alcohol intake, avoiding prolonged use of exogenous hormone therapy, and avoiding excessive radiation exposure. These behaviors, while not proven in clinical trials to reduce risk, are likely to be beneficial. Information on them can be provided as a prevention strategy in LMCs, although the methods of information delivery and follow-up will depend on financial and personnel resources. While the magnitude of absolute risk reduction based on risk factor management is somewhat unclear, any of these health behaviors can reduce risk for other chronic diseases, so they may be of high interest for general public health in both LMCs and high-income countries. Several strategies are available for reducing breast cancer risk in countries with lower resources, although few of them have completed rigorous clinical-trial testing. ${ }^{14}$

\section{Early detection}

Strategies to reduce breast cancer risk cannot eliminate the majority of breast cancers that develop in LMCs, which remains the most prominent cancer among women even in countries that lack the most common "Westernized" breast cancer risk factors. ${ }^{15}$ Early stage detection is a key determinant of breast cancer outcome, because earlier staged disease has lower breast cancer mortality and requires fewer resources to provide effective treatment. ${ }^{10}$

Public education is a key first step in implementing breast health programs. The approach and scope of the public education program determine both the success of early detection as measured by stage at diagnosis, and will also drive the breadth of resource allocation needed for program implementation. Public education programs must include health education messages conveying the idea that breast cancer is curable in the majority of women when it is detected early, diagnosed accurately and treated appropriately. ${ }^{16}$ To optimize success, communication methods need to be adapted to the cultural boundaries and taboos that invariably surround breast cancer diagnosis, but may differ among and within countries, depending on the social context and common health care belief systems. 
Breast cancer screening modalities include breast self-examination (BSE), clinical breast examination (CBE) and screening mammography. The effectiveness and efficiency of each of these strategies must be considered in the context of resource availability and population-based need, which also determines the primary goal of a screening program. Screening mammography is the only single modality having been shown in prospective randomized trials to improve breast cancer mortality, but its cost is prohibitive in many settings. ${ }^{17}$ A survey of oncology experts reported that over $90 \%$ of Latin American countries had no national law or guideline for mammography screening. ${ }^{18}$ When screening mammography is employed in LMCs, target populations and screening intervals need to consider what is optimal for the overall population and within the scope of available resources. ${ }^{10}$

Unlike screening mammography, CBE has not been shown to improve breast cancer mortality in a randomized trial. Studies of CBE in LMCs have been undertaken, but have been problematic and inconclusive. ${ }^{19}$ Inferential studies suggest that clinical down-sizing of palpable disease should improve outcome. ${ }^{20}$ However, the establishment of clinical evaluation, which includes patient history as well as CBE, is a practical and necessary prerequisite for the operation of any early detection program, especially in an LMC where patients typically present with advanced stage disease, and at a minimum provides a practical linkage between breast cancer early detection and diagnosis.

\section{Diagnosis}

Breast diagnosis consists of clinical evaluation, imaging and laboratory studies, and surgical pathology. ${ }^{11}$ Obtaining a patient's history, both specific to her breasts and to her general health, provides important information for clinical assessment of breast disease and comorbid disease that might influence breast cancer therapy choices. Focused CBE and complete physical examination provides guidance on the extent of disease, presence of metastatic disease, and ability to tolerate more aggressive therapeutic regimens.

Breast imaging, initially with ultrasound and at higher resource levels with diagnostic mammography improves preoperative diagnostic assessment, and also permits image guided needle sampling of suspicious lesions. Diagnostic mammography, while helpful for breast conservation therapy, is not mandatory in LMCs when these resources are lacking. ${ }^{21}$ Additional imaging studies facilitate metastatic work-up and therefore patient treatment selection. Selected laboratory studies are required for the safe administration of cytotoxic chemotherapy, which is a basic level resource for treatment of node-positive, estrogen receptor (ER) negative and locally advanced disease.

Quality surgical pathology is critical to breast program function. ${ }^{11,22}$ The availability of predictive tumor markers, especially ER testing, is critical to proper selection of cancer therapy when endocrine therapies are available, although quality assessment of immunohistochemical (IHC) testing is important to avoid false negative results. Interdisciplinary communication underlies the basis of success for breast diagnostic programs at all economic levels. Furthermore, the interaction of the pathologist with the radiologist and the surgeon (interdisciplinary team collaboration) is critical in the examination and reporting of the pathology specimen, since the clinical situation in which the specimen was obtained can markedly influence the significance of certain pathological findings, and in the case of cancer, can be critical in determining accurate tumor staging.

\section{Treatment}

Surgical therapy. The ability to perform modified radical mastectomy (MRM) is the mainstay of locoregional treatment at the basic level of breast health care. While the MRM (total mastectomy + level I/ II axillary lymph node dissection) is considered fundamental surgical training in high-income countries, surgeons from LMCs may have had less exposure to the procedure and may not be knowledgeable about the operation's proper technical execution. A retrospective review of patients referred from outside institutions to Tata Memorial Hospital in Mumbai, India found that of 424 who had undergone "therapeutic" surgical interventions, 191 (45\%) were judged to have incomplete surgery. Of these, 153 patients underwent completion revision surgery and 123 had residual axillary nodes including 64 patients (52\%) with metastatic lymph nodes found to have been left behind in the axillary bed. ${ }^{23}$

Radiation therapy. The availability of radiation therapy allows for consideration of breast conserving therapy, post-mastectomy chest wall radiation, and for palliation of painful or symptomatic metastases. ${ }^{24}$ Radiation therapy has a major impact on local tumor control for early and locally advanced disease; and effective and safe radiation therapy can improve overall survival rates as well. 25,26

Use of evidence-based doses and techniques is crucial for achieving the best possible clinical outcomes and reduced complications. The cost of developing and maintaining a radiation therapy program should be balanced against the cost of management of complications 
of treatment, both contributing to the overall management costs of breast cancer patients. ${ }^{24}$ For patients with distant metastases, radiation therapy is an effective tool for palliation, especially for bone, brain and soft tissue metastases.

There is a huge insufficiency of radiation therapy resources in LMCs (Table I). ${ }^{27}$ In Latin American countries, the prevalence of radiotherapy units varies more than 8 -fold (Table II). Paraguay has only 3 radiotherapy units in the entire country, meaning that each unit must serve over 2 million people. By comparison, the United States has one DIRAC registered radiation therapy unit per 160,000 persons in the population, a statistic that does not include private radiation facilities not yet registered in the IAEA database.

As a result, there is a need to provide the necessary equipment, but also to improve the quality, the technique and the utilization of resources in an optimal and sustainable fashion. Radiation therapy can be delivered with a cobalt-60 unit or a linear accelerator (linac) along with other quality assurance tools. ${ }^{24}$ Although linac is considered the preferred therapy in most settings, telecobalt machines are a reasonable alternative in LMCs. Of note, linac requires consistent electricity for powering and water for cooling the equipment. Thus, in some low-income settings, telecobalt may be more practical

Table I

WorldWide ReSOURCES IN RADIOTHERAPY AS REPORTED IN THE IAEA/WHO DiRectory Of Radiotherapy CEnTERS (DIRAC) in 2005 for deVeloping and deVeloped countries (North America, Western Europe, Australasia AND Japan, With incomplete data especially from North AMERICA AND Japan). ${ }^{27}$

\begin{tabular}{lcrr} 
& Developing countries N (\%) & Developed countries N (\%) & All N (\%) \\
Countries in DIRAC & $129(81 \%)$ & $30(19 \%)$ & $159(100 \%)$ \\
\hline Teletherapy & $3340(35 \%)$ & $4883(65 \%)$ & $5778(100 \%)$ \\
\hline Radionuclide & $2112(69 \%)$ & $715(31 \%)$ & $2827(100 \%)$ \\
\hline Linear Accelerators & $1228(18 \%)$ & $4168(82 \%)$ & $5396(100 \%)$ \\
\hline Brachytherapy & $1187(34 \%)$ & $1698(66 \%)$ & $2885(100 \%)$
\end{tabular}

Table II

Prevalence of radiotherapy treatment centers as reported in the IAEA/WHO Directory of Radiotherapy Centers (DIRAC) as COMPAREd to the POPUlation for SELECTED Latin AMERICAN COUNTRIES AND the UNITED StATES.TECHNOLOGY DISTRIBUTION VARIES SIGNIFICANTLY ACCORDING TO REGION, TYPE OF INSTITUTION AND ETHNIC/SOCIAL GROUP, SUCH THAT SIGNIFICANT INEQUITY IN ACCESS TO TECHNOLOGY COMMONLY EXISTS WITHIN COUNTRIES

\begin{tabular}{|c|c|c|c|}
\hline Countries & Country population* & Number of radiation therapy centers ${ }^{\ddagger}$ & Radiation therapy centers per million inhabitants \\
\hline Paraguay & $6,127,000$ & 3 & 0.49 \\
\hline Bolivia & $9,525,000$ & 6 & 0.63 \\
\hline Ecuador & $|3,867,76|$ & 9 & 0.65 \\
\hline Uruguay & $3,340,000$ & 14 & 4.19 \\
\hline Chile & $|6,82|, 000$ & 24 & 1.43 \\
\hline Colombia & $44,603,000$ & 46 & 1.03 \\
\hline Venezuela & $28,018,018$ & 47 & 1.68 \\
\hline Mexico & $106,182,500$ & 96 & 0.90 \\
\hline Argentina & $40,301,927$ & 98 & 2.43 \\
\hline Brazil & $188,029,000$ & 191 & 1.02 \\
\hline United States of America & $305,579,000$ & 1875 & 6.14 \\
\hline
\end{tabular}

* Countries population in http://en.wikipedia.org/wiki/List_of_countries_by_population, accessed Nov. 5th, 2008

¥ Registered radiotherapy centers as reported in the Directory of Radiotherapy Centers (DIRAC) in http://www-naweb.iaea.org/nahu/dirac/login.asp\# accessed Nov. 5th, 2008 
to provide. In either circumstance, applying safe and effective treatment requires well-trained staff, support systems, geographic accessibility, and the initiation and completion of treatment without undue delay. ${ }^{28}$ To specifically address these issues in LMCs, the International Atomic Energy Agency (IAEA) established in 2004 the "Programme of Action for Cancer Therapy" (PACT) to seek and direct funds from individuals, charitable trusts, foundations and the public and private sectors to help patients in poor countries receive appropriate cancer treatment, an initiative that has been welcomed by the World Health Organization (WHO).

In early stage breast cancer, radiation therapy is an essential part of breast conservation treatment. Standard treatment includes the irradiation of the entire breast with an additional boost to the tumor site and should be delivered after treatment planning with at least 2-dimensional imaging. Among patients with node-positive disease, post-mastectomy radiation therapy has shown local control and overall survival advantages. However, if access to radiation were specifically limited, preference for post-mastectomy radiation could be given to patients with 4 or more positive lymph nodes. Chest wall and supraclavicular lymphatic irradiation is considered standard treatment with locally advanced disease. However, routine axilla irradiation is not recommended due to heightened lymphedema risk. When indicated, internal mammary chain irradiation may be considered when used with cardiac safe radiation techniques and appropriate planning. The long-term risks of cardiac morbidity and mortality require special attention to the volume of heart and lungs exposed, and attempts should be made to reduce exposure to these tissues. Alternative treatment schedules like hypofractionated radiation and partial breast irradiation are at present investigational and should not be considered as standard care in LMCs.

Systemic therapy. The use of systemic therapy cytotoxic chemotherapy is effective in the treatment of all biologic subtypes of breast cancer, but is more resource intensive to provide. ${ }^{12}$ The provision of endocrine therapy requires relatively few specialized resources, but optimally requires knowledge of hormone receptor status to assure treatment of patients most likely to benefit. HER2-targeted therapy is very effective in tumors that overexpress the HER2/ neu oncogene, but cost largely prevents the use of this treatment in LMCs.

Tamoxifen remains useful and recommended for patients with estrogen receptor-positive tumors in LMCs. Aromatase inhibitors (AIs) give better results than tamoxifen and are recommended for countries with enhanced and maximal resources, but cost constraints make tamoxifen a very reasonable alternative to AIs. No overall survival benefit has been attributed to AIs over tamoxifen. Hormonal therapy should be used after surgery for at least 5 years.

Trastuzumab combined with taxanes yields high pathological response rates in patients with HER2/neuoverexpressing tumors, is recommended in countries with enhanced and maximal resources, and should be made available in countries with lower levels of resources at lower costs because of their high efficacy. In patients who are candidates for it, trastuzumab should be continued for a total of one year. Clinical trials to evaluate the role of shorter durations of trastuzumab are appropriate for LMCs and should be encouraged.

Management of locally advanced disease. Recent data shows that locally advanced breast cancer (LABC) and metastatic breast cancer (MBC) are the most common stages at presentation, $60-80 \%$ of cases, in most LMCs. ${ }^{29-31}$ While the incidence of LABC has decreased significantly in developed countries with enhanced and maximal resources due to widespread education and increasing utilization of screening mammography, and as fully discussed in a separate report of this BHGI supplement, ${ }^{32}$ $\mathrm{LABC}$ remains a daily challenge for oncologists in LMCs where limitations to proper management include also lack of local data, cultural circumstances, and weak inefficient health care systems.

Preoperative chemotherapy is the preferred primary therapy for LABC, because it allows early assessment of sensitivity to treatment as well as breast conservation. ${ }^{32}$ Clinical assessment of chemosensitivity may be particularly helpful, because emerging data suggests that there could be differences in host metabolism of systemic treatment agents-tamoxifen, alkylating agents, taxanes-- on genetic bases, with associated efficacy and toxicity differences among genetically different populations. ${ }^{33,}{ }^{34}$ Research specifically directed at differences among groups in response to systemic therapy may be warranted. ${ }^{35}$ While the preferred initial treatment of LABC is systemic therapy, if optimal chemotherapy and evaluation are not available, then primary MRM is acceptable. However, it should be recognized that without systemic therapy, surgery alone for LABC is unlikely to improve outcome, given the high likelihood of systemic relapse, so the role of MRM without adjuvant treatment for LABC should be viewed primarily as palliative therapy.

After responding to systemic therapy, most LABC patients will require a modified radical mastectomy followed by radiation therapy. ${ }^{24}$ Locoregional therapy decisions should be based on both the pretreatment clinical extent of disease and the pathologic extent of 
the disease after chemotherapy. Accordingly, physical examination and imaging studies that accurately define the initial extent of disease are required before treatment. ${ }^{36}$ The success of breast conservation after preoperative chemotherapy depends on careful patient selection and achieving negative surgical margins. Adjuvant breast radiation is indicated for all patients treated with breast conservation. For patients treated with mastectomy, chest-wall and regional nodal radiation should be considered for those who present with clinical stage III disease or have histologically positive lymph nodes after preoperative chemotherapy. ${ }^{36}$

Metastatic and inflammatory breast cancer should be initially managed with preoperative therapy irrespective of resource level. Standard preoperative therapy includes anthracycline-based chemotherapy. The addition of sequential taxane after anthracyclinebased chemotherapy improves pathological responses and breast-conservation rates, though may not improve survival. The combination is considered appropriate treatment at the enhanced and maximal level; however, costs and lack of clear survival benefit do not justify its use at limited resource levels. CMF combination chemotherapy is less potent than anthracycline and taxanes, but may be used in its classical schedule in LMCs because of lower costs and lesser complications. The role for preoperative endocrine therapy remains to be better defined, but appears to be feasible and acceptable in elderly women. ${ }^{32}$

\section{Guideline dissemination and implementation (D\&I) research}

The dominant paradigm even now in the medical community is that good research and publication should be sufficient to ensure the translation of scientific findings into general practice. ${ }^{37}$ Unfortunately, a landmark IOM report from 2001 clearly identified the failure of much scientific innovation to be translated into practice. ${ }^{38,}$

${ }^{39}$ More recently, Rubenstein and Pugh separated the IOM's second translational block -clinical research to practice- into two parts: clinical research to guidelines and guidelines to practice. ${ }^{40} \mathrm{D} \& \mathrm{I}$ researchers maintain that the process is complex, and they have begun to identify factors and processes critical to the adoption of new technologies and practices. ${ }^{41}$ Although there has already been some D\&I work on assessing readiness for change, it has usually focused on just one component, such as providers or health units, or has focused on intention without considering self-efficacy or environment. As a conclusion in her extensive review of the implementation literature, Greenhalgh notes the need for more research on system readiness for innovation and for more studies evaluating implementation of specific interventions. ${ }^{42}$

A review of available information strongly suggests a crucial role for research in applying the experience and knowledge of high-income societies to the challenges of women and breast cancer throughout the world. A recent survey of oncology experts from Latin American countries found that $94 \%$ of the surveyed experts consider clinical-epidemiologic research development on breast cancer insufficient in their country. The main reasons identified were insufficient economic retribution and lack of available time.

Very little research on guideline implementation has been done in LMCs. It is necessary to see whether the basic frameworks and instruments being described in high-income countries apply in these very different environments and what adaptation is needed to make them both valid and feasible. A systematic program of research to develop appropriate readiness assessment instruments and to identify effective implementation strategies is now needed in a variety of LMCs. As we move toward the adoption, implementation, and maintenance of the new evidence-based principles embodied in the BHGI guidelines, it is critical that careful evaluation be incorporated in the efforts, to ensure that lessons about effectiveness and efficiency are captured. It is precisely because resources are scarce in these countries that it is even more imperative for LMCs to adopt effective practices as quickly as possible, and that implementation approaches are designed with limited resources in mind. ${ }^{37}$

\section{References}

I. Parkin DM, Bray F, Ferlay J, Pisani P. Global cancer statistics, 2002. CA Cancer J Clin 2005;55(2):74- 108.

2. Stewart B, Kleihues PE. World cancer report. Lyon: IARCPress, 2003. 3. Ferlay J, Bray F, Pisani P, Parkin DM. GLOBOCAN 2002: Cancer Incidence, Mortality and Prevalence Worldwide. IARC CancerBase No. 5. version 2.0, (http://www-dep.iarc.fr/) Lyon: IARCPress, 2004: Last accessed December 13, 2008.

4. Goldhirsch A, Glick JH, Gelber RD, Coates AS, Thurlimann B, Senn HJ. Meeting highlights: international expert consensus on the primary therapy of early breast cancer 2005. Ann Oncol 2005; I6(10):1569-83.

5. Carlson RW,Anderson BO, Burstein HJ, Cox CE, Edge SB, Farrar WB, et al. Breast cancer.J Natl Compr Canc Netw 2005;3(3):238-89.

6. Anderson BO, Braun S, Carlson RW, Gralow JR, Lagios MD, Lehman C, et al. Overview of breast health care guidelines for countries with limited resources. Breast J 2003;9 Suppl 2:S42-50.

7. Anderson BO, Shyyan R, Eniu A, Smith RA, Yip CH, Bese NS, et al. Breast cancer in limited-resource countries: an overview of the Breast Health Global Initiative 2005 guidelines. Breast J 2006; I2 Suppl I:S3-I5.

8. Anderson BO,Yip CH, Smith RA, Shyyan R, Sener SF, Eniu A, et al. Guideline implementation for breast healthcare in low-income and 
middle-income countries: Overview of the Breast Health Global Initiative Global Summit 2007. Cancer 2008; I I3(8 suppl):222I-43.

9. Sloan FA, Gelband H, eds. Cancer Control Opportunities in Low- and Middle-Income Countries (summary) Washington, D.C.:The National Academies Press, 2007:1-16.

10. Yip CH, Smith RA, Anderson BO, Miller AB, Thomas DB,Ang E-S, et al. Breast health guideline implementation in low- and middle-income countries (LMCs): Early detection resource allocation. Cancer 2008; I 3(8 suppl):2244-56.

II. Shyyan R, Sener SF,Anderson BO, Fernandex Garrote LM, Hortobagyi GN, Ibarra JA, et al. Guideline implementation for breast healthcare in low-income and middle-income countries: Diagnosis resource allocation. Cancer 2008; I I3(8 supple):2257-68.

12. Eniu A, Carlson RW, El Saghir NS, Bines J, Bese NS, Vorobiof D, et al. Breast health guideline implementation in low- and middle-income countries (LMCs): Treatment resource allocation. Cancer 2008; I 338 suppl):2269-8I.

13. Harford J,Azavedo E, Fischietto M. Breast health guideline implementation in low- and middle-income countries (LMCs): Breast healthcare program resource allocation. Cancer 2008; I 3 (8 suppl):2282-96. 14. McTiernan A, Porter P, Potter JD. Breast cancer prevention in countries with diverse resources. Cancer 2008; I 3 (8 supple):2325-30 15. Porter P."Westernizing" women's risks? Breast cancer in lowerincome countries. N Engl J Med 2008;358(3):2I3-6.

16. Kreps GL, Sivaram R. Strategic health communication across the continuum of breast cancer care in limited-resource countries. Cancer 2008; I I3(8 supple):233I-37.

17. Weiss NS. Breast cancer mortality in relation to clinical breast examination and breast self-examination. Breast J 2003;9 Suppl 2:S86-9. 18. Cazap E, Buzaid A, Garbino C, de la Garza J, Orlandi F, Schwartsmann $\mathrm{G}$, et al. Breast Cancer in Latin America: Results of the Latin American and Caribbean Society of Medical Oncology/Breast Cancer Research Foundation Expert Survey. Cancer 2008; I 3 (8 suppl):2359-65. 19. Pisani P, Parkin DM, Ngelangel C, Esteban D, Gibson L, Munson M, et al. Outcome of screening by clinical examination of the breast in a trial in the Philippines. Int J Cancer 2006; I I8(I):149-54.

20. Duffy SW,Tabar L,Vitak B,Warwick J.Tumor size and breast cancer detection: what might be the effect of a less sensitive screening tool than mammography? Breast J 2006; I2 Suppl I:S91-5.

2I. Nadkarni MS, Gupta PB, ParmarVV, Badwe RA. Breast conservation surgery without pre-operative mammography-A definite feasibility. Breast J 2006

22. Masood S,Vass L, Ibarra JA, Ljung B-M, Stalsberg H, Eniu A, et al. Breast pathology guideline implementation in low- and middle-income countries. Cancer 2008; I I3(suppl):2297-304

23. Thorat MA, Rangole A, Nadkarni MS, ParmarV, Badwe RA. Revision surgery for breast cancer: Single institution experience. Cancer 2008; I I3(8 suppl):2347-52.

24. Bese NS, Munshi A, Budrukkar A, Elzawawy A, Perez CA. Breast radiation therapy guideline implementation in low- and middle-income countries. Cancer 2008; I I3(8 suppl):2305-I4.

25. Nielsen HM, Overgaard M, Grau C, Jensen AR, Overgaard J. Study of failure pattern among high-risk breast cancer patients with or without postmastectomy radiotherapy in addition to adjuvant systemic therapy: long-term results from the Danish Breast Cancer Cooperative Group DBCG $82 \mathrm{~b}$ and $\mathrm{c}$ randomized studies. J Clin Oncol 2006;24(I5):2268-75.
26. Ragaz J, Olivotto IA, Spinelli J], Phillips N, Jackson SM,Wilson KS, et al. Locoregional radiation therapy in patients with high-risk breast cancer receiving adjuvant chemotherapy: 20-year results of the British Columbia randomized trial.J Natl Cancer Inst 2005;97(2): I 6-26.

27. Salminen E, Izewska J,Andreo P. IAEA's role in the global management of cancer-focus on upgrading radiotherapy services. Acta Oncol 2005;44(8):816-24.

28. Bese NS, Kiel K, El-Gueddari Bel K, Campbell OB,Awuah B,Vikram $B$. Radiotherapy for breast cancer in countries with limited resources: program implementation and evidence-based recommendations. Breast J 2006; 12 Suppl I:S96-102

29. Parkin DM, Fernandez LM. Use of statistics to assess the global burden of breast cancer. Breast J 2006;12 Suppl I:S70-80.

30. Hortobagyi GN, de la Garza Salazar J, Pritchard K,Amadori D, Haidinger R, Hudis CA, et al. The global breast cancer burden: variations in epidemiology and survival. Clin Breast Cancer 2005;6(5):391-40I.

3I. El Saghir NS, Khalil MK, Eid T, El Kinge AR, Charafeddine M, Geara $\mathrm{F}$, et al. Trends in epidemiology and management of breast cancer in developing Arab countries: a literature and registry analysis. Int J Surg 2007;5(4):225-233.

32. El Saghir NS, Eniu A, Carlson RW,Aziz Z,Vorobiof D, Hortobagyi GN. Locally advanced breast cancer:Treatment guideline implementation with particular attention to low- and middle-income countries. Cancer 2008; I I3(8 suppl):23 I5-54.

33. Goetz MP, Rae JM, Suman VJ, Safgren SL, Ames MM,Visscher DW, et al. Pharmacogenetics of tamoxifen biotransformation is associated with clinical outcomes of efficacy and hot flashes. J Clin Oncol 2005;23(36):9312-8.

34. DeMichele A,Aplenc R, Botbyl J, Colligan T,Wray L, Klein-Cabral M, et al. Drug-metabolizing enzyme polymorphisms predict clinical outcome in a node-positive breast cancer cohort. J Clin Oncol 2005;23(24):5552-9. 35. Love RR. Defining a global research agenda for breast cancer. Cancer 2008; I I3(8 suppl):2366-7I

36. Buchholz TA, Lehman CD, Harris JR, Pockaj BA, Khouri N, Hylton NF, et al. Statement of the science concerning locoregional treatments after preoperative chemotherapy for breast cancer: a National Cancer Institute conference. J Clin Oncol 2008;26(5):79I-7.

37. McCannon CJ, Berwick DM, Massoud MR. The science of large-scale change in global health. JAMA 2007;298(16):1937-1939.

38. Committee on Quality of Health Care in America, Institute of Medicine. Crossing the quality chasm: $A$ new health system for the 21 st century (Executive Summary) Washington: National Academy Press, 200I:I - 22.

39. IOM committee calls for complete revamping of health care system to achieve better quality. Qual Lett Healthc Lead 200I;I3(3): I4-5. 40. Rubenstein LV, Pugh J. Strategies for promoting organizational and practice change by advancing implementation research.J Gen Intern Med 2006;2I Suppl 2:S58-64.

4I. Grimshaw J, Eccles M,Thomas R, MacLennan G, Ramsay C, Fraser $\mathrm{C}$, et al. Toward evidence-based quality improvement. Evidence (and its limitations) of the effectiveness of guideline dissemination and implementation strategies 1966-1998.J Gen Intern Med 2006;2I Suppl 2: SI $4-20$.

42. Greenhalgh T, Robert G, Macfarlane F, Bate P, Kyriakidou O.

Diffusion of innovations in service organizations: systematic review and recommendations. Milbank Q 2004;82(4):58I-629. 